\title{
Sarampión: la enfermedad, epidemiología, historia y los programas de vacunación en Chile
}

\author{
Luis Delpiano, Leonor Astroza y Jorge Toro
}

\section{Measles: the disease, epidemiology, history and vaccination programs in Chile}

Measles, one of most important inmuno-preventable diseases, remains as a worldwide concern issue with an important morbidity and mortality. Particularly in the America region declared free of measles in 2010 by WHO, they still appear imported cases that origin outbreaks of variable magnitude in susceptible subjects usually none vaccinated which is the current situation in Santiago, the capital city of Chile. In this review we present characteristics of the etiological agent, the disease, epidemiological aspects with national historical focus, impact of immunization programs and outbreaks in Chile, in order to contribute to knowledge and management of this always present public health problem.

Key words: Measles, morbillivirus, exanthem, epidemiology, vaccines.

Palabras clave: Sarampión, morbillivirus, exantema, epidemiología, vacunas.

\section{Introducción}

$\mathrm{S}$ arampión es una enfermedad de origen viral altamente contagiosa, eliminada en gran parte del mundo gracias a la implementación de programas de vacunación. En la actualidad, aún es capaz de originar brotes particularmente en población susceptible no vacunada determinando alta carga de morbilidad y mortalidad $^{1,2}$.

\section{Agente etiológico}

Probablemente ya afectaba a la especie humana desde hacía más de 5.000 años, el sarampión fue introducido en América en el siglo XVII por los colonizadores europeos causando cientos de muertos entre los nativos, lo que facilitó la conquista ${ }^{3}$. Recién en el año 1954 J. Enders y T. Peebles informaron sobre el aislamiento del virus del sarampión en la sangre y secreciones de pacientes mediante la inoculación en cultivos celulares humanos y de simios. La primera cepa de virus, denominada Edmonston, por el paciente de quien se aisló, fue sub-cultivada en diferentes tipos de líneas celulares para la preparación de una primera vacuna experimental ${ }^{4}$.

El virus sarampión es un virus de simetría helicoidal, ARN de polaridad negativa no segmentado, perteneciente a la familia Paramyxoviridae y al género morbillivirus, con aproximadamente 15.900 nucleótidos codificando ocho proteínas virales y que posee además una ARN polimerasa unida al ARN. La nucleocápside helicoidal está rodeada por una envoltura lipídica y posee tres proteínas relevantes en patogenia, la proteína $\mathrm{M}$ (no glicosilada), la glicoproteína HN (glicosilada) con actividad hemaglutinina y neuroaminidasa y la glicoproteína $\mathrm{F}$, que participa en fenómenos de fusión. Se transmite por aerosoles con puerta de entrada en el aparato respiratorio o por contacto directo con secreciones respiratorias originando una enfermedad sistémica. El ser humano es el único reservorio de este agente etiológico ${ }^{5,6}$.

\section{Patogenia y clínica}

La infección se inicia luego de la unión de la hemaglutinina $(\mathrm{H})$ a su receptor celular; pronto la proteína de fusión (F) induce fusión viral con la membrana celular liberando su complejo ribonucleoproteico al citoplasma para que, luego de transcripción y replicación, se generen nuevas partículas virales que germinan fuera de la célu$1 \mathrm{a}^{7,8}$. Desde el año 2000 se identificó al receptor CD150, tanto para el virus sarampión salvaje como de laboratorio; este receptor se encuentra en la superficie de timocitos, macrófagos, células dendríticas además de linfocitos $\mathrm{T}$ y B. Recientemente, un receptor lectina tipo $\mathrm{C}$ expresado por células dendríticas, también fue identificado como receptor del virus sarampión; esta unión participa modulando a través de un toll-like receptor, un aumento en la producción de IL-10 por la célula dendrítica ${ }^{9,10}$. El virus sarampión, también infecta células epiteliales, endoteliales, y neuronales sugiriendo la existencia de otros receptores para este mecanismo ${ }^{11}$. Con lo anterior,
Hospital Clínico San Borja Arriarán (LD). Programa Nacional de Inmunizaciones, MINSAL 2000-2009 (LA) (Actual Unidad Programación Médica Hospital Clínico San Borja Arriarán).

Departamento Epidemiología, MINSAL 1990-1995 (JT).

(Actual: Apoyo a la Gestión. Dirección APS, SS

Viña del Mar-Quillota).

Los autores declaran no tener conflictos de interés.

Recibido: 17 de julio de 2015 Aceptado: 24 de julio de 2015

Correspondencia a: Luis Delpiano M. ludelpia@vtr.net 
el concepto clásico de que el virus infecta y se replica en células del aparato respiratorio, para diseminarse luego a linfonodos regionales, desde donde a través de monocitos disemina a una fase virémica (Tabla 1), hoy en día motiva a nuevos cuestionamientos ya que ni las células epiteliales, ni los monocitos expresan CD150. En el modelo animal y a través de fluorescencia, se ha demostrado que las principales células foco de la replicación viral del sarampión son los linfocitos T y B (con receptores CD150) y que éstos son quienes participan en la diseminación virémica en macacos; así entonces, esta gran afectación de linfocitos de memoria, se relacionaría con la inmunosupresión propia de esta enfermedad ${ }^{12}$

\begin{tabular}{|c|c|}
\hline Día & Evento \\
\hline 0 & $\begin{array}{l}\text { El virus sarampión, a través de gotitas, toma contacto con la superficie epitelial de la naso- } \\
\text { faringe y posiblemente de la conjuntiva ocular }\end{array}$ \\
\hline $1-2$ & Extensión de la infección a linfonodos regionales \\
\hline $2-3$ & Viremia primaria \\
\hline $3-5$ & $\begin{array}{l}\text { Multiplicación del virus sarampión en el epitelio respiratorio en el sitio inicial } \\
\text { de infección y en el sistema reticuloendotelial regional y en sitios distantes }\end{array}$ \\
\hline $5-7$ & Viremia secundaria \\
\hline 7-11 & Clínica de exantema y compromiso respiratorio u otros sitios de acuerdo a la viremia \\
\hline $11-14$ & Virus en la sangre, tracto respiratorio, piel y otros órganos \\
\hline $15-17$ & Disminución de la viremia así como el contenido viral en distintos órganos \\
\hline
\end{tabular}

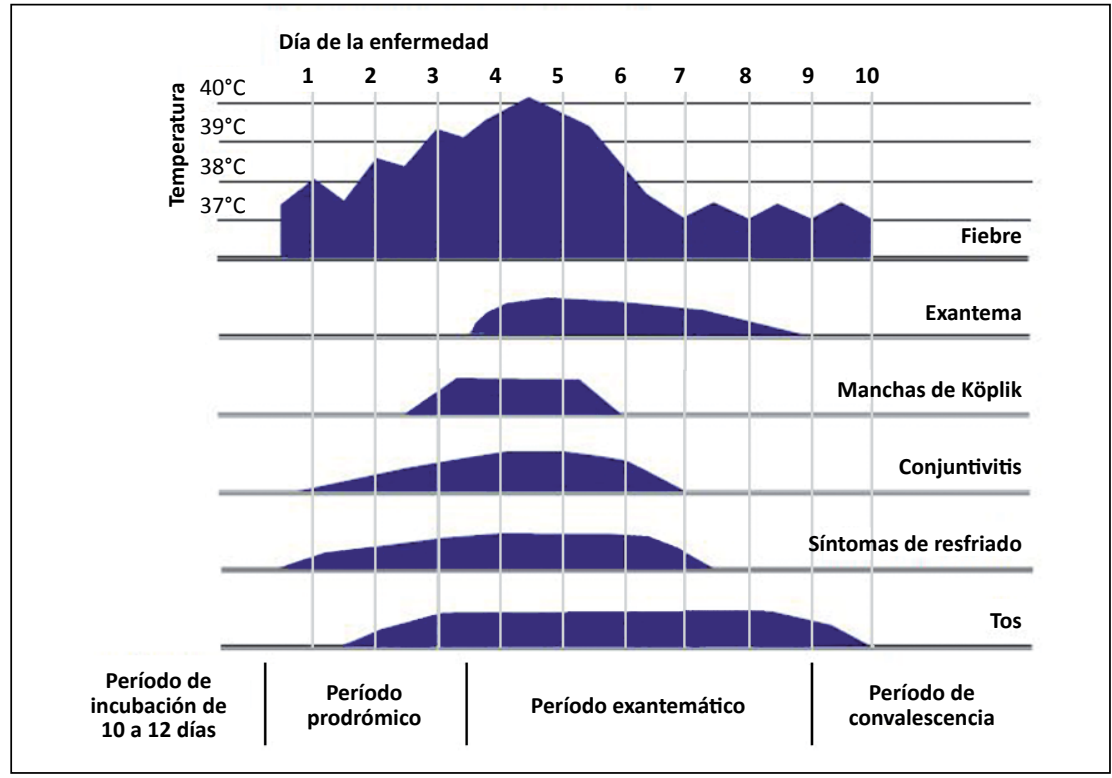

Figura 1. Evolución temporal de las características clínicas del sarampión. Tomado del manual para el diagnóstico de laboratorio de la infección por los virus del sarampión y de la rubéola. OMS, segunda edición 2006.
Después de un período de incubación promedio de 10 días, se inician los primeros síntomas conocidos como pródromo (Figura 1), período caracterizado por fiebre (en niños con pico de $39 \mathrm{a} 40^{\circ} \mathrm{C}$ ), coriza y/o tos, conjuntivitis y lesiones de Köplik (Figura 2) (definidas como patognomónicas), síntomas que se van intensificando, dando paso en el día 14 post contacto a la aparición del exantema de tipo morbiliforme o máculo-papular generalizado ${ }^{9}$ (Figura 3). Los enfermos, se consideran infectantes desde cuatro días antes hasta cuatro después de la aparición del exantema, período en el que tienen altas concentraciones virales en sangre y en fluidos respiratorios, y por la presencia de síntomas respiratorios, se ve facilitada la difusión viral².

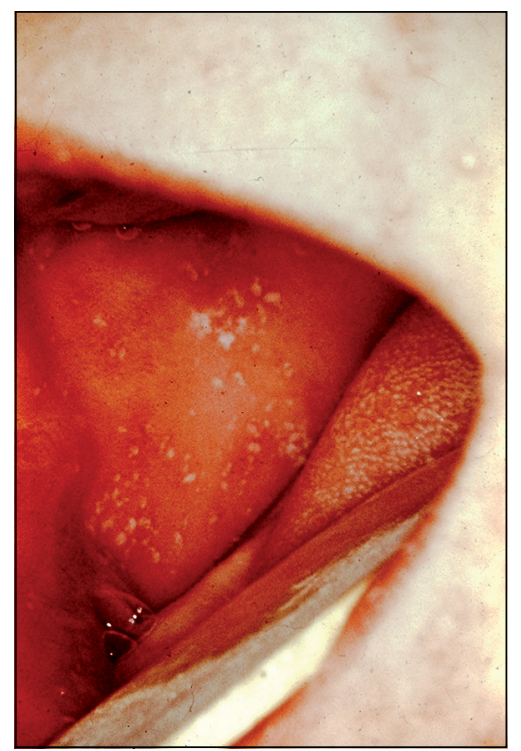

Figura 2. Manchas de Köplik en la cara interna de las mejillas, características de esta enfermedad.

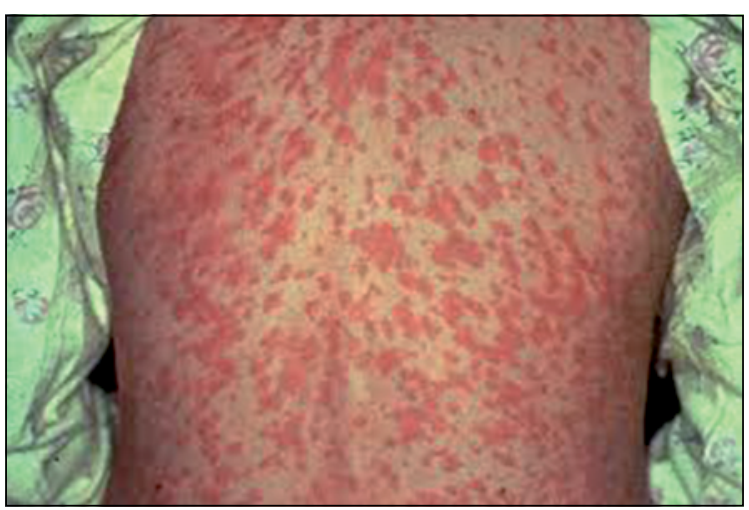

Figura 3. Exantema máculo-papular que lleva al nombre popular de "alfombrilla". 


\begin{tabular}{|c|c|}
\hline Categoría & Hallazgos inmunológicos \\
\hline Leucocitos & $\begin{array}{l}\text { Defecto en la motilidad de neutrófilos } \\
\text { Leucopenia (incluye linfocitos y neutrófilos) } \\
\text { Disminución de linfocitos T y B } \\
\text { Disminución de células con actividad natural killer } \\
\text { Disminución células T helper } \\
\text { Supresión prolongada de producción interleukina-12 } \\
\text { Depresión prolongada de producción de interferón } \alpha\end{array}$ \\
\hline Interferón $\alpha$ & Niveles plasmáticos elevados \\
\hline Receptor soluble de interleukina-2 & Niveles plasmáticos elevados \\
\hline Plaquetas & Reducción del recuento periférico \\
\hline Complemento & Frecuente activación patológica y reducción de C1q, C4, C3 y C5 \\
\hline Inmunoglobulinas & Reducción IgA e IgE, con aumento de IgM \\
\hline Hipersensibilidad cutánea retardada & Deprimida \\
\hline Proteína C reactiva & Elevada al inicio del exantema \\
\hline Circulación de complejos inmunes & Detectado en $25 \%$ de pacientes en segunda semana luego exantema \\
\hline Respuesta in vitro de linfocitos a Candida sp & Suprimida \\
\hline
\end{tabular}

El sarampión está considerado entre las infecciones más contagiosas de la infancia. El exantema se inicia habitualmente en la cara, y de forma centrifuga se disemina a tronco y extremidades. Y aunque la enfermedad determina una fuerte respuesta inmune humoral y celular estimulando inmunidad específica de por vida, produce a la vez una importante inmunosupresión que dura varias semanas (Tabla 2) aumentando la susceptibilidad a infecciones secundarias ${ }^{13}$.

Las complicaciones descritas en niños menores incluyen otitis media aguda (5 a 15\%), neumonía (5 a 10\%), laringitis obstructiva y ocasionalmente diarrea aguda, las que se presentan con mayor frecuencia en países subdesarrollados o en presencia de desnutrición o inmunodepresión. También se describe como complicación grave la encefalitis post infecciosa en 1 por 1.000 casos, igual valor de 1 por 1.000 casos se reconoce para su letalidad ${ }^{14}$.

\section{Diagnóstico}

En la actualidad, el diagnóstico de sarampión debe basarse en tres elementos: manifestaciones clínicas, epidemiología y laboratorio. Por definición, un caso presuntivo o sospechoso se basa en síntomas debiendo indagarse factores de riesgo epidemiológico como viajes a zonas con endemia de sarampión (Figura 4); necesariamente un caso sospechoso debe ser sometido a pruebas de laboratorio confirmatorias. La Organización Mundial de la Salud (OMS) entrega como definición de caso sospechoso a: "cualquier persona con exantema máculo-papular generalizado, fiebre superior a $38^{\circ} \mathrm{C}, y$ uno de los siguientes: tos, coriza o conjuntivitis"; agregando además "cualquier persona en que un profesional de la salud sospeche sarampión"15,16. Sin embargo, la presentación clínica puede ser variable en lactantes menores, pacientes inmunocomprometidos o individuos previamente vacunados.

Para su confirmación diagnóstica se dispone de pruebas serológicas con mediciones de IgG e IgM específicas ${ }^{17}$, biología molecular con aplicación RPC-TR y aislamiento viral. Resulta relevante recalcar que los títulos de IgM, que son confirmatorios de enfermedad, se detectan desde el $3^{\circ}$ día del exantema y se mantienen positivos por $30 \mathrm{a}$ 60 días en la mayoría de los sujetos enfermos y que, para la evaluación de IgG se requiere de la elevación de cuatro veces el título de ellos entre fase aguda y convalecencia de la enfermedad. La ejecución de RPC, de rápido procesamiento con muestras respiratorias, confirma la enfermedad y permite la genotipificación del agente ${ }^{2,18}$. Estudios con biología molecular y secuenciación han permitido definir ocho linajes del virus salvaje (A, B, C, D, E, F, G y H) y dentro de ellos reconocer 23 genotipos (A, B1, B2, B3, C1, C2, D1, D2, D3, D4, D5, D6, D7, D8, D9, D10, E, F, G1, G2, G3, H1, y H2). La genotipificación, herramienta fundamental de la vigilancia epidemiológica promovida por la OMS, y parte del diagnóstico, permite analizar brotes epidémicos y determinar el origen autóctono o importado de un tipo en particular ${ }^{19}$. 
Figura 4. Reporte de casos de sarampión a la OMS desde diciembre de 2014 hasta mayo del 2015 (período de 6 meses) http://www. who.int/immunization/monitoring_surveillance/burden/ vpd/surveillance type/active/ big_measlesreportedcases6months_PDF.pdf

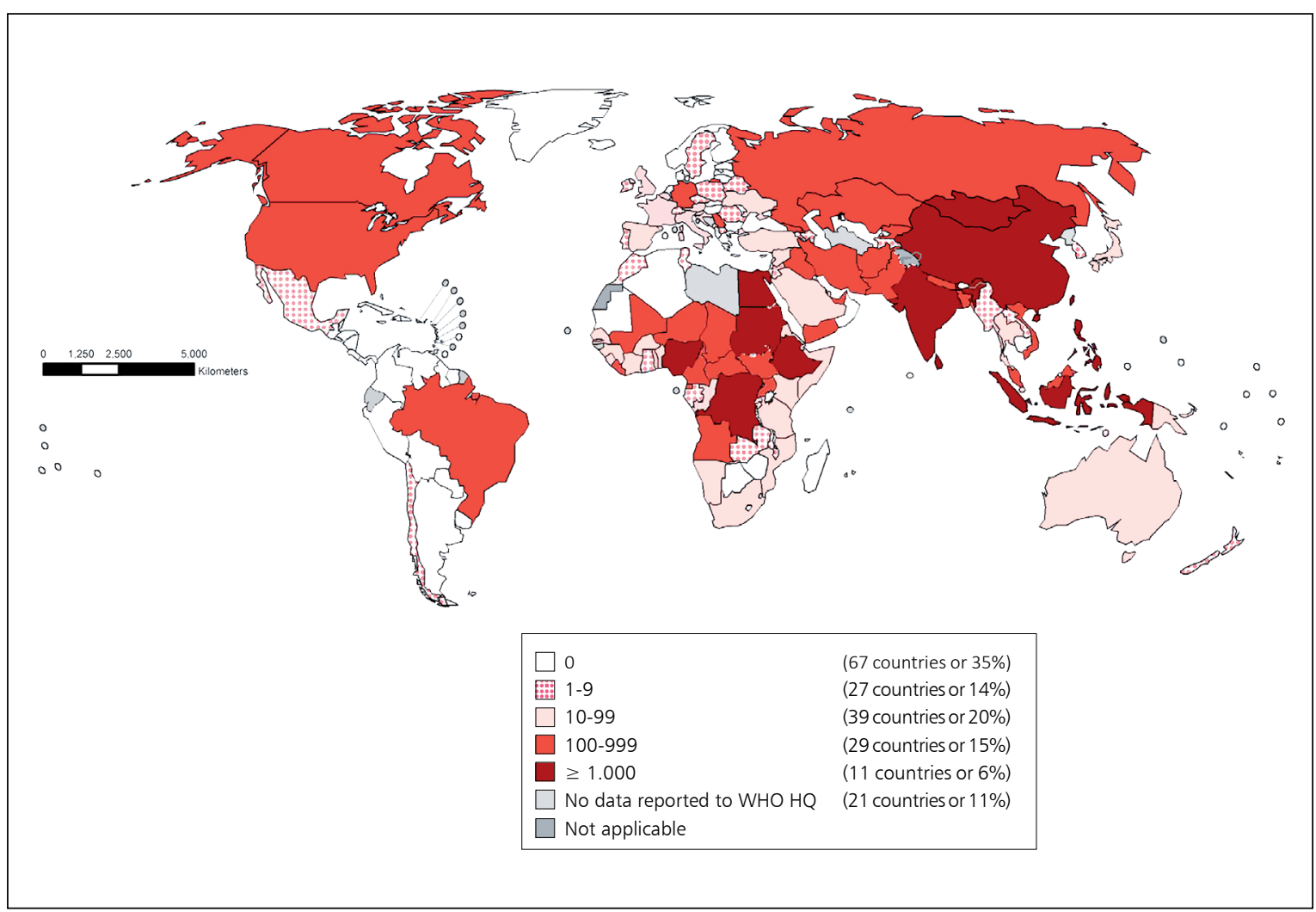

\section{Tratamiento}

No existe terapia antiviral específica para el sarampión. La indicación de hospitalización debiera estar motivada sólo por el diagnóstico de complicaciones graves asociadas. Se aconseja medidas de soporte con manejo de la fiebre, hidratación y adecuado apoyo nutricional. La administración de vitamina $\mathrm{A}$, sugerida por la OMS a fin reducir letalidad, se focaliza principalmente para niños en países en vía de desarrollo o subdesarrollados (mayor incidencia de hipovitaminosis) la que se debe indicar por dos días consecutivos con dosis de 200.000 UI en mayores de un año ${ }^{20}$. A lactantes entre 6 a 12 meses se recomienda 100.00 UI y bajo de 6 meses administrar 50.000 UI. En niños con evidencia clínica de deficiencia de vitamina A, se recomienda una tercera dosis 2 a 4 semanas después de haber cursado sarampión ${ }^{2,14}$.

\section{Prevención}

La medida preventiva más relevante es la inmunización con vacuna. La primera vacuna atenuada disponible se desarrolló luego de sucesivos pasajes en embrión de pollo de la cepa Edmonston, con alto reporte de eventos adversos. Una mayor cantidad de pasajes de atenuación, permitió obtener la cepa Edmonston B o Schwarz para la licencia de una vacuna en 1965 y finalmente en 1968 se licenció una vacuna con cepa Moraten (aún más atenuada, del inglés more attenuated). Estas vacunas atenuadas, todas pertenecientes al genotipo $\mathrm{A}$, tienen mutaciones que la diferencian del virus salvaje y presentan menor tropismo por linfocitos ${ }^{21}$.

\section{Epidemiologia y programa de inmunización}

Antes de la introducción de la vacuna, el sarampión era una enfermedad "obligada" en la niñez, de tal manera que a los 20 años de edad más de $90 \%$ de la población mundial ya la había tenido. De comportamiento endémico global, causaba epidemias de grandes proporciones cada dos o tres años, principalmente a fines de invierno, en primavera en regiones de clima templado, y durante todo el año en regiones de clima tropical.

Según cifras de la OMS, en los años 80, el sarampión causaba cerca de 2,6 millones de muertes en el orbe, y luego de intensas campañas de vacunación, el año 2013 hubo registro de 145.700 muertes por sarampión en todo el mundo, lo que traduce 400 muertes por día y 16 por hora, con evidente mejoría en cifras de letalidad, pero 


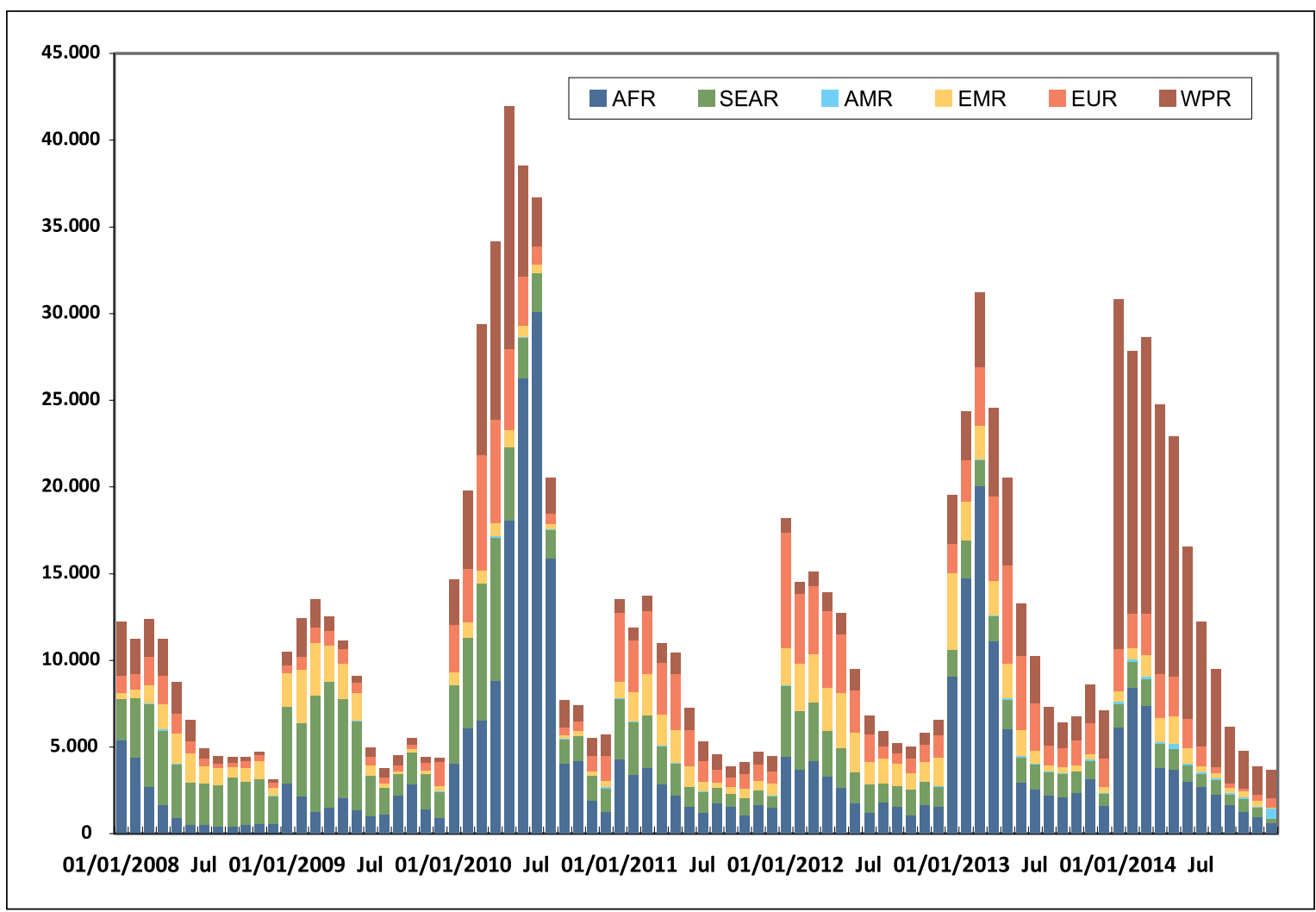

persistiendo como problema de salud pública aún en numerosos países ${ }^{22}$. La distribución mundial de casos reportados a la OMS por distintos países entre 2008 y 2014 se presenta en la Figura 5.

La vacunación contra el sarampión ha proporcionado grandes beneficios de salud pública, reduciendo la mortalidad mundial por esta causa en $75 \%$ entre 2000 y 2013 . En el año 2013, aproximadamente $84 \%$ de la población infantil mundial recibió, a través de los servicios de salud habituales, una dosis de vacuna contra el sarampión cercano al año de vida. En el 2000, ese porcentaje fue de $73 \%$. Se estima que entre los años 2000 a 2013, la vacuna contra el sarampión evitó 15,6 millones de muertes, lo que la convierte en una de las mejores inversiones en salud pública.

En América, los brotes recientes de sarampión en los Estados Unidos de América (E.U.A.) y Brasil, a partir de casos importados desde otras regiones del mundo, sugieren que las tasas de inmunización en algunas áreas han descendido por debajo de los niveles necesarios para prevenir la propagación de la enfermedad. El sarampión se considera eliminado de las Américas desde 2002 debido a la ausencia de transmisión endémica de la enfermedad ${ }^{23}$. Un comité internacional de verificación está compilando datos probatorios para declarar a la región libre del sa- rampión, lo que haría de las Américas la primera región del mundo en eliminar la enfermedad, en línea con éxitos similares como la eliminación de la viruela en la década de 1970 y de la poliomielitis en los 90', logros que han sido resultado de los esfuerzos regionales por alcanzar altas coberturas de vacunación, a través de programas regulares de inmunización y campañas masivas de vacunación.

Sin embargo, la región no ha estado exenta de problemas, a partir de casos importados se originan brotes regionales. La genotipificación de casos identificada en brotes de Latinoamérica entre 2010 y 2014 se presenta en la Tabla 3. Esta caracterización genética de los virus en circulación es un componente crítico de vigilancia de laboratorio del sarampión y de los estudios epidemiológicos moleculares. La combinación de análisis molecular y la investigación de un caso estándar, proporciona una información sensible para describir las rutas de transmisión del virus y para documentar la interrupción de la transmisión endémica del sarampión. La ausencia de genotipo(s) endémicos es uno de los criterios para verificar la eliminación del sarampión en un país o región.

A principios de este año, según reporte OPS/OMS, se habían confirmado 147 casos de sarampión en cuatro países de América. De ese total, 121 casos fueron en los E.U.A., vinculados principalmente al brote que empezó
Figura 5. Distribución de casos de sarampión reportados por mes en las regiones de la OMS, 2008-2014. Fuente: reporte de países a OMS. 


\begin{tabular}{|c|c|c|c|c|}
\hline Año & Brotes con 1 caso & Brotes con 2-5 casos & Brotes con $6-20$ casos & Brotes $>20$ casos \\
\hline 2010 & FRG-2 (D4) & BRA-1 (B3) & $\begin{array}{l}\text { ARG-1 (B3) } \\
\text { BRA-1 (B3) }\end{array}$ & BRA-1 (B3) \\
\hline 2011 & $\begin{array}{l}\text { ARG-1 (D4) } \\
\text { BRA-5 (D4) } \\
\text { CHI-1 (D9) } \\
\text { JAM-1 (B3) } \\
\text { MEX-3 (D4) } \\
\text { BRA-2 (NA) }\end{array}$ & $\begin{array}{l}\text { ARG-1 (D4) } \\
\text { BRA-6 (D4) } \\
\text { CHI-2 (D4) } \\
\text { DOR-1 (D4) } \\
\text { PAN-1 (D4) }\end{array}$ & $\begin{array}{l}\text { COL-1 (D4) } \\
\text { FRG-1 (D4) } \\
\text { GLP-1 (D4) }\end{array}$ & $\begin{array}{l}\text { BRA-1 (D4) } \\
\text { ECU-1 (B3) }{ }^{(a)}\end{array}$ \\
\hline 2012 & $\begin{array}{l}\text { ARG-1 (D4) } \\
\text { COL-1 (D4) } \\
\text { VEN-1 (D4) }\end{array}$ & BRA-1 (NA) & BRA-1 (D8) & ECU-1 (B3)(a) \\
\hline 2013 & $\begin{array}{l}\text { BRA-2 (D8) } \\
\text { BRA-1 (D4) } \\
\text { BRA-2 (NA) } \\
\text { COL-1 (NA) }\end{array}$ & BRA-2 (D8) & & BRA-1 (D8)(b) \\
\hline 2014 & $\begin{array}{l}\text { ARG-1 (D8) } \\
\text { BRA-1 (B3) } \\
\text { BRA-1 (NA) }\end{array}$ & BRA-2 (D8) & & BRA-1 (D8)(b) \\
\hline Total de brotes e información de genotipo & $27(78 \%)$ & 17 (94\%) & $6(100 \%)$ & $6(100 \%)$ \\
\hline
\end{tabular}

en diciembre pasado en Disneylandia, California; un solo caso en México también se vinculó a ese brote y de los restantes casos, 21 tuvieron lugar en Brasil y cuatro en Canadá. Los casos en Brasil forman parte de un brote más grande que comenzó a principios de 2013 y que ha enfermado a más de 700 personas en 31 municipios. Entre 2011 y mayo de 2015 (antes de los casos confirmados

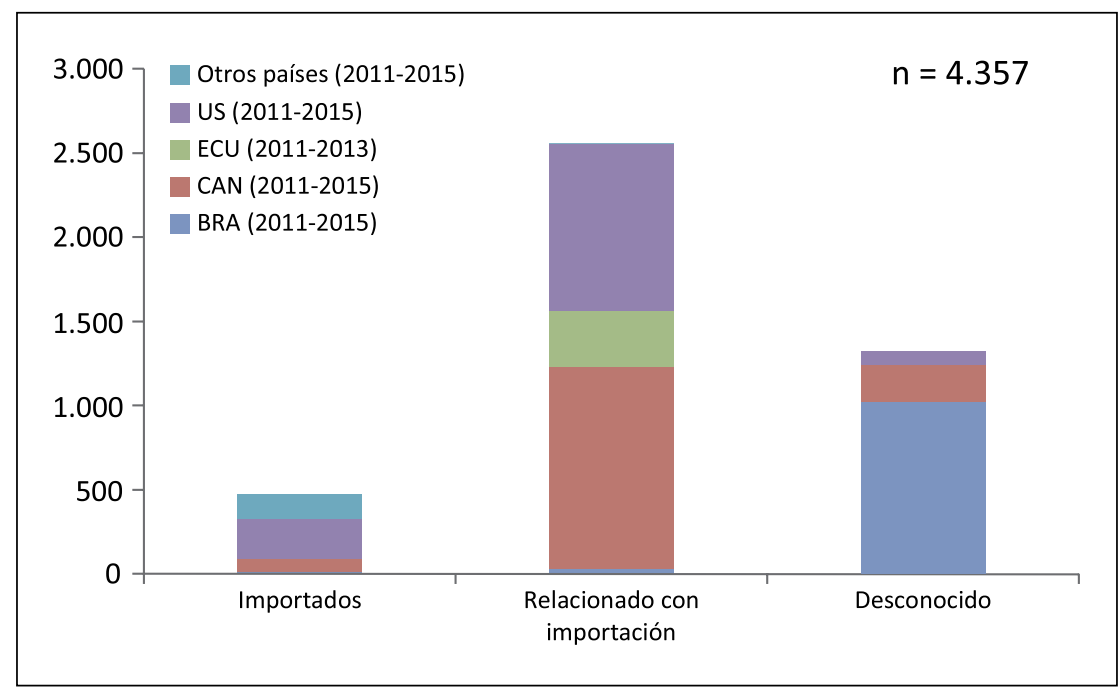

Figura 6. Casos confirmados de sarampión según situación de importación en las Américas. 20112015*. Fuente: MESS, ISIS e informe de los países. *Datos al 21 de mayo de 2015. en Chile), la región registró un total de 4.357 casos de sarampión; cuyos casos iniciales obedecen a importación con diseminación posterior en susceptibles (Figura 6).

En Chile existe información sobre epidemias de sarampión desde 1899, ya que a fines de ese año, comenzó en Santiago para luego extenderse en el país una de las epidemias más letales de esta enfermedad y que continuó hasta el año 1900. Según relata el profesor Puga Borne "fue la más tremenda experiencia que tuvimos en esa época, pues la epidemia nos ha llevado una generación entera" 24 . Si se observa la tendencia de los casos de sarampión desde mediados de siglo a la fecha, se puede dividir este período en dos fases: antes de la introducción de la vacuna en los esquemas nacionales de inmunización y posterior a su introducción a partir de 1964. El número de casos, tasas de incidencia y letalidad de sarampión en Chile desde 1939 se presentan, con el valor de corresponder a una serie histórica, en la Tabla 4.

Período pre vacuna (1839-1963): Los casos se mantienen en valores que oscilan en rangos de 1.000 a 10.000 casos anuales. A partir de 1958, los casos se duplican y las tasas son cuatro veces superiores a lo observado hasta el momento. La misma tendencia se observa en las muertes, alcanzando su máximo en 1962 con un total de 2.465 muertes y una tasa de letalidad de 6,6\%. Entre 1951 y 1963 se observan brotes que se sucedían cada 4 ó 5 años y la letalidad varía proporcionalmente con el número de casos. 
Tabla 4. Número de casos, tasa de incidencia (x 100.000 habitantes) y letalidad por sarampión. Chile 1939-2015

\begin{tabular}{|c|c|c|c|c|c|c|c|c|c|}
\hline Año & $\mathrm{n}$ de casos & Tasa & $\mathrm{n}$ de muertes & Letalidad & Año & $\mathrm{n}$ de casos & Tasa & n de muertes & Letalidad \\
\hline 1939 & 2.625 & 72,2 & 370 & 7,4 & 1979 & 34.390 & 313,3 & 154 & 0,4 \\
\hline 1940 & 1.809 & 35,6 & 240 & 4,7 & 1980 & 3.844 & 34,5 & 10 & 0,3 \\
\hline 1941 & 3.632 & 70,2 & 226 & 4,4 & 1981 & 6.527 & 57,6 & 17 & 0,3 \\
\hline 1942 & 5.409 & 102,8 & 400 & 7,6 & 1982 & 9.438 & 81,9 & 16 & 0,2 \\
\hline 1943 & 888 & 16,6 & 125 & 2,3 & 1983 & 6.752 & 57,6 & 22 & 0,3 \\
\hline 1944 & 668 & 12,3 & 60 & 1,1 & 1984 & 4.785 & 40,1 & 10 & 0,2 \\
\hline 1945 & 6.491 & 117,2 & 245 & 4,4 & 1985 & 17.101 & 141,1 & 26 & 0,1 \\
\hline 1946 & 1.278 & 22,7 & 131 & 2,3 & 1986 & 12.563 & 101,9 & 24 & 0,2 \\
\hline 1947 & 1.899 & 33,2 & 149 & 2,6 & 1987 & 2.623 & 20,9 & 1 & 0,04 \\
\hline 1948 & 3.142 & 54,1 & 143 & 2,5 & 1988 & 45.079 & 353,6 & 68 & 0,1 \\
\hline 1949 & 2.503 & 42,4 & 204 & 3,5 & 1989 & 13.008 & 100,4 & 14 & 0,1 \\
\hline 1950 & 1.093 & 13,0 & 54 & 0,9 & 1990 & 1.958 & 14,8 & 0 & 0,0 \\
\hline 1951 & 3.746 & 60,3 & 117 & 3,1 & 1991 & 2.098 & 15,6 & 0 & 0,0 \\
\hline 1952 & 4.224 & 66,6 & 45 & 1,1 & 1992 & 397 & 2,9 & 2 & 0,5 \\
\hline 1953 & 7.429 & 114,6 & 406 & 5,5 & 1993 & 1 & 0,01 & 0 & 0,0 \\
\hline 1954 & 6.672 & 100,7 & 735 & 11,0 & 1994 & 0 & 0,0 & 0 & 0,0 \\
\hline 1955 & 11.831 & 174,6 & 542 & 4,6 & 1995 & 0 & 0,0 & 0 & 0,0 \\
\hline 1956 & 10.771 & 155,4 & 453 & 4,2 & 1996 & 0 & 0,0 & 0 & 0,0 \\
\hline 1957 & 12.588 & 177,4 & 667 & 5,4 & 1997 & 256 & 0,4 & 0 & 0,0 \\
\hline 1958 & 28.320 & 389,9 & 1.575 & 5,6 & 1998 & 6 & 0,04 & 0 & 0,0 \\
\hline 1959 & 14.596 & 196,3 & 1.147 & 7,9 & 1999 & 34 & 0,2 & 0 & 0,0 \\
\hline 1960 & 32.720 & 429,7 & 2.116 & 6,5 & 2000 & 0 & 0,0 & 0 & 0,0 \\
\hline 1961 & 38.469 & 493,2 & 1.822 & 4,7 & 2001 & 0 & 0,0 & 0 & 0,0 \\
\hline 1962 & 37.649 & 471,0 & 2.455 & 6,6 & 2002 & 0 & 0,0 & 0 & 0,0 \\
\hline 1963 & 28.543 & 348,5 & 2.243 & 7,7 & 2003 & 1 & 0,0 & 0 & 0,0 \\
\hline 1964 & 35.941 & 428,6 & 3.264 & 9,1 & 2004 & 0 & 0,0 & 0 & 0,0 \\
\hline 1965 & 13.110 & 152,8 & 1.211 & 9,2 & 2005 & 0 & 0,0 & 0 & 0,0 \\
\hline 1966 & 23.604 & 269,2 & 1.734 & 7,3 & 2006 & 0 & 0,0 & 0 & 0,0 \\
\hline 1967 & 15.702 & 175,3 & 1.134 & 7,2 & 2007 & 0 & 0,0 & 0 & 0,0 \\
\hline 1968 & 7.146 & 78,2 & 398 & 5,6 & 2008 & 0 & 0,0 & 0 & 0,0 \\
\hline 1969 & 9.538 & 102,3 & 335 & 3,5 & 2009 & 1 & 0,0 & 0 & 0,0 \\
\hline 1970 & 22.127 & 232,8 & 599 & 2,7 & 2010 & 0 & 0,0 & 0 & 0,0 \\
\hline 1971 & 17.671 & 182,6 & 601 & 3,4 & 2011 & 6 & 0,04 & 0 & 0,0 \\
\hline 1972 & 6.299 & 63,9 & 159 & 2,5 & 2012 & 0 & 0,0 & 0 & 0,0 \\
\hline 1973 & 3.868 & 38,6 & 57 & 1,5 & 2013 & 0 & 0,0 & 0 & 0,0 \\
\hline 1974 & 16.806 & 165,0 & 242 & 1,4 & 2014 & 0 & 0,0 & 0 & 0,0 \\
\hline 1975 & 8.413 & 81,3 & 177 & 2,1 & $2015^{*}$ & 9 & 0,05 & 0 & 0,0 \\
\hline 1976 & 2.542 & 24,2 & 63 & 2,5 & \multirow{3}{*}{\multicolumn{5}{|c|}{$\begin{array}{l}\text { Fuente: Anuarios de Enfermedades de Notificación Obligatoria. DEIS y Departamento } \\
\text { de Epidemiología MINSAL 2014. *Se agregan casos confirmados por ISP hasta } 14 \\
\text { de julio de } 2015 \text {. }\end{array}$}} \\
\hline 1977 & 1.062 & 10,0 & 5 & 0,5 & & & & & \\
\hline 1978 & 15.381 & 142,2 & 55 & 0,4 & & & & & \\
\hline
\end{tabular}




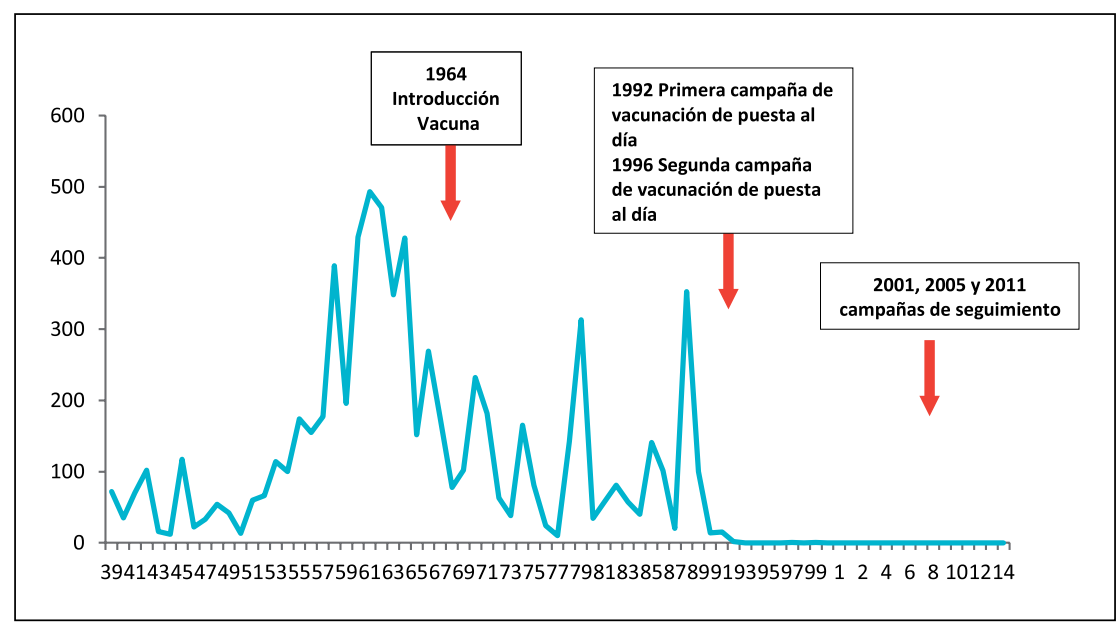

Figura 7. Tasa de incidencia de sarampión por 100.000 habitantes. Chile 1939-2014, asociado a inclusión de la vacuna en el PAI-PNI y campañas de vacunación. Fuente: Anuarios de Enfermedades de Notificación Obligatoria. Boletín Epidemiológico Ministerio de Salud.

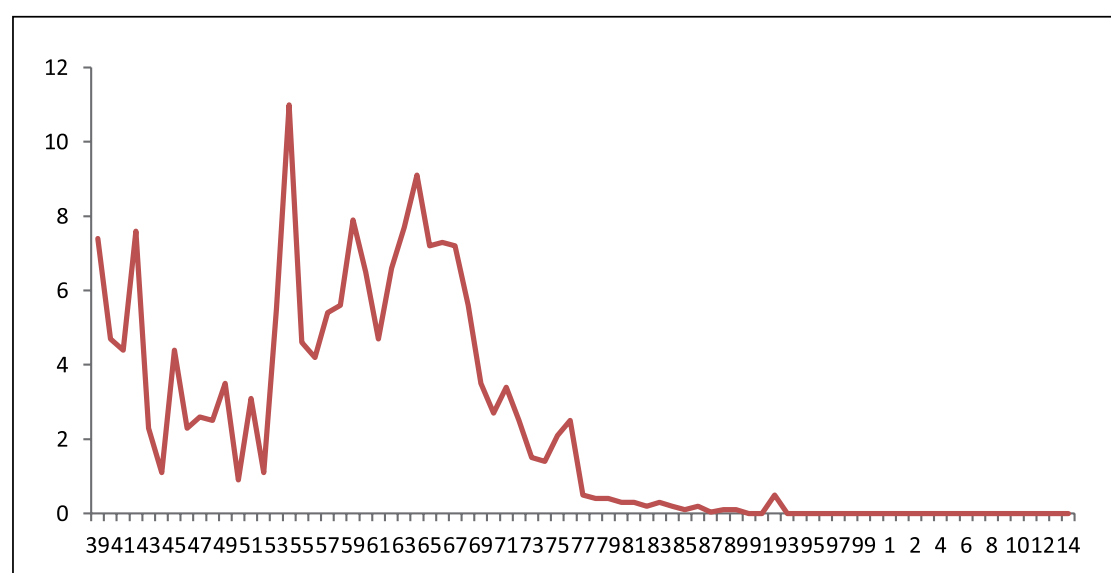

Figura 8. Tasa de letalidad de sarampión. Chile 1939-2014. Fuente: Anuarios de Enfermedades de Notificación Obligatoria. Boletín Epidemiológico Ministerio de Salud.

Tabla 5. Edad y dosis de vacuna anti sarampión incluida en Programa Nacional de Inmunización (PNI) de Chile desde 1964 a la fecha

\begin{tabular}{llc} 
Año & Edad & $\mathbf{n}$ de dosis \\
1964 a 1979 & 8 meses & 1 dosis \\
1980 a 1981 & 8 meses y revacunación en segundo básico & 1 dosis \\
1982 & 8 meses y entre los 18 meses a 4 años & 1 dosis \\
1983 a 1985 & $\begin{array}{l}12 \text { meses y revacunación a los } 18 \text { meses para los niños vacunados } \\
\text { antes de los } 12 \text { meses de edad }\end{array}$ & 1 dosis \\
1986 a 1989 & 12 meses & 1 dosis \\
1990 & 12 meses con trivírica (sarampión, rubéola, parotiditis) y bivírica & 1 dosis \\
1992 a la fecha & 12 meses y revacunación en primero básico con trivírica & 1 dosis \\
\hline
\end{tabular}

Periodo post vacuna (1964 en adelante): A partir del año 1964, cuando se introdujo la vacuna en el calendario de vacunación, los casos comenzaron a descender reduciéndose a un tercio en el año 1965. Esta importante reducción de casos no se observó en los años siguientes, sino hasta los años 1968-1969. En los años posteriores se observaron cada cuatro años brotes de menor intensidad; sin embargo, entre 1979 y 1988, los brotes cambian el patrón cíclico observado hasta el momento alcanzando una magnitud similar a los brotes observados en el período pre vacunación.

En 1990 el Programa Nacional de Inmunizaciones inició la vacunación de los niños de un año de edad con vacuna SPR (sarampión-parotiditis-rubéola) y en 1991 se incorporó una segunda dosis de esta vacuna en los escolares de primer año básico. Con posterioridad a la introducción de esta segunda dosis, los casos disminuyeron de 13.000 en 1989 a 2.000 en 1990 y 1991 . En resumen, desde que se introdujo la vacuna contra el sarampión en Chile en 1964, se ha logrado una reducción significativa de las tasas de morbilidad y mortalidad por esta enfermedad (Figuras 7 y 8). La morbilidad se redujo de 428 por 100.000 en 1964 a 0,4 en 1997. Entre 1993 y 1996 no se presentaron casos y los casos confirmados en 1997 , 1998, 1999 y 2003 corresponden a casos importados o relacionados con importación.

Los esquemas de vacunación, explicitando entre otras el número de dosis y los intervalos de administración cuando corresponde, son informados a los equipos de salud a través de Normas o Manuales distribuidos a los distintos establecimientos de salud públicos o privados donde se administran las vacunas; estos documentos han experimentado numerosas modificaciones desde su introducción programática (Tabla 5).

Sobre la administración de media dosis de vacuna durante los años 1971 a 1981 (10 años) no se ha encontrado evidencia de este hecho. La primera Norma Técnica elaborada y editada por el Sub-Departamento de Protección de la Salud del Servicio Nacional de Salud del año $1972^{25}$, en la página 24 que se refiere a las características de la vacuna sarampión, en el punto 6.4 donde habla de Técnica de Vacunación y dosis expresamente específica "Inyectar por vía subcutánea, la dosis recomendada de acuerdo al envase en uso". Del mismo modo el Manual de Inmunizaciones de octubre de $1981^{26}$ elaborado y editado por el Departamento de Apoyo a los Programas del Ministerio de Salud, página 16, punto 5.4: Indicaciones y dosis textualmente dice: "Dosis individual 0,5 $\mathrm{ml}$ y 0,7 $\mathrm{ml}$ según el laboratorio. Se debe administrar a los 8 meses de edad y en el escolar en el segundo básico".

Por otra parte, el Boletín Informativo de OPS de mayo de $1979^{27}$ en el que se consignan los esquemas de vacunación para las distintas vacunas de los países de las Américas, registra para Chile la vacuna a los 8 meses de 


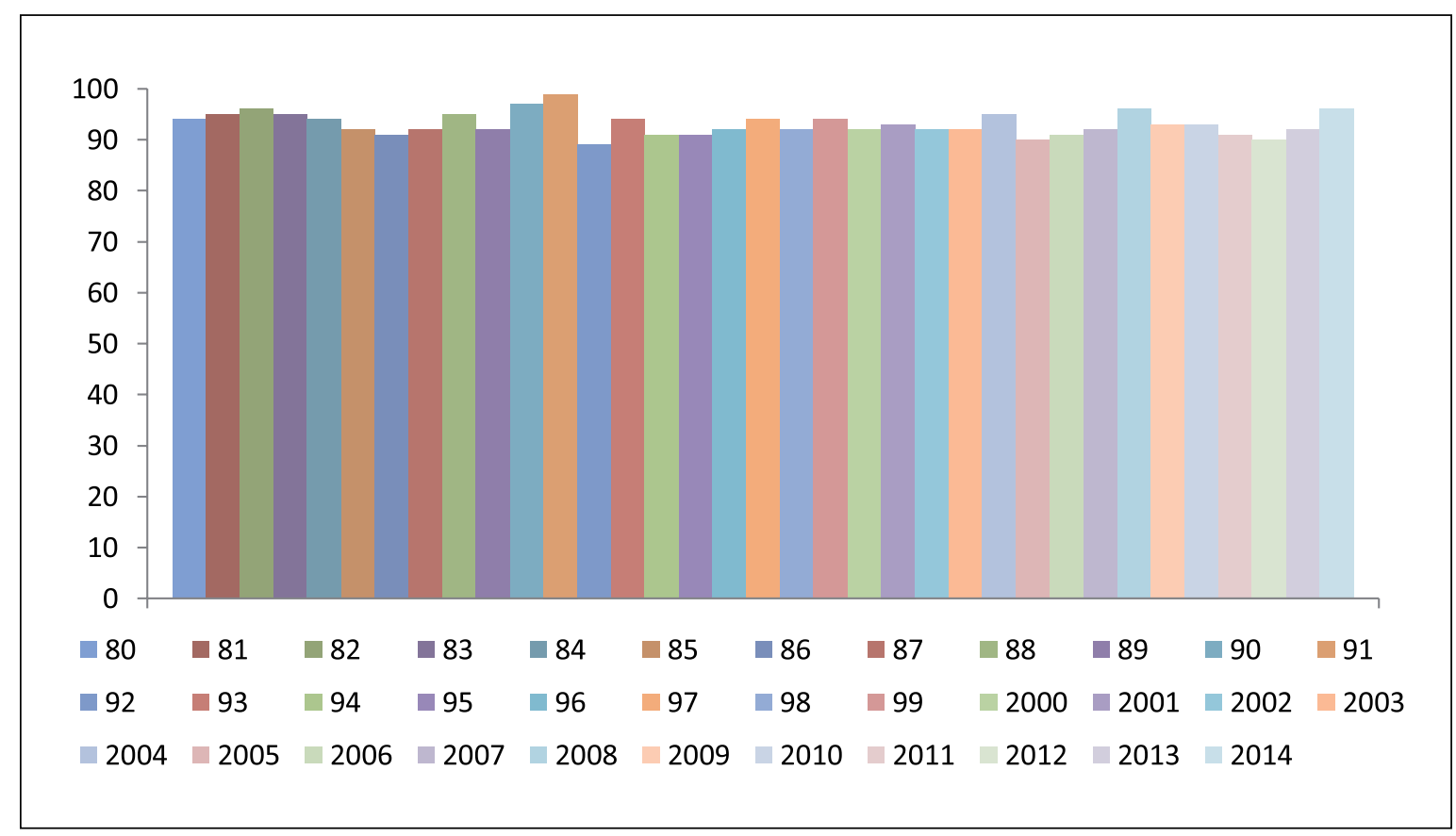

edad con una dosis. Teniendo en cuenta estos antecedentes podríamos concluir con cierto grado de seguridad que la administración de media dosis de vacuna no ocurrió durante un período tan extenso como de 10 años. Así entonces, la situación de menor seropositividad asignada a la cohorte de chilenos nacidos entre 1971 a 1981 que los identifica como población susceptible de riesgo actual, puede deberse a otras razones. En revisiones de la literatura internacional, no se encontraron resultados sobre eficacia de la vacuna cuando se administra una dosis menor a la recomendada por el fabricante. Lo que si se documenta es la pérdida de la eficacia en las siguientes situaciones $^{28}$ :

1. Termo-estabilidad: Antes de 1980 todas las vacunas sarampión disponibles eran termolábiles. De acuerdo a recomendaciones de la OMS, para que una vacuna sarampión sea eficaz, no debe perder más de $1 \log 10$ después de la exposición durante una semana a $37^{\circ} \mathrm{C}$ o a una temperatura más elevada.

2. La vacuna sarampión liofilizada pierde su actividad una vez reconstituida. La disminución de la actividad es de $50 \%$ al cabo de $1 \mathrm{~h}$ a $37^{\circ} \mathrm{C}, 70 \%$ al cabo de tres horas entre $22^{\circ} \mathrm{C}$ y $23^{\circ} \mathrm{C}$, y puede ser inactivada a $35-37^{\circ} \mathrm{C}$, al cabo de 2 a $7 \mathrm{~h}$.

3. Si se conserva $\mathrm{a}+4^{\circ} \mathrm{C}$ la vacuna reconstituida, mantiene una actividad superior a 1.000 DICT durante al menos $24 \mathrm{~h}$. La pérdida de actividad se estima en 0,015 log DICT50 por hora. Sin embargo, no es aconsejable el uso de la vacuna una vez diluida, más allá de las tres horas, por dos razones:

- La disminución de la actividad de la vacuna se asocia a una débil respuesta en anticuerpos.

- El riesgo de contaminación de la vacuna diluida, especialmente cuando se usa envase multidosis.

Favorablemente y respecto de cifras de cobertura de inmunización en la población objetivo, durante la década de los 80, las coberturas nacionales de vacunación al año de edad superaron el $90 \%$, alcanzando la cifra más alta en 1991 (99\%). La misma situación se observa para los años comprendidos entre 1992 y 2008. A partir del 2009, la cobertura de vacunación cae a $93 \%$, alcanza $90,6 \%$ el 2012 y a 90,1\% el 2013, observándose una recuperación en el 2014 en que la cobertura informada llega a 96\%. En la Figura 9 se puede apreciar los valores de cobertura de la vacunación anti-sarampión al año de edad en Chile desde 1980 a 2014 y que en los últimos años no alcanzan a 95\%. Así también, en la Figura 10 se observan las coberturas de vacunación registradas en el primero año de educación básica en el país desde 1991 a 2014 con cifras bajo el umbral esperado, entregando cifras de 78,7\% (2011), 74,7\% (2012), 75,3\% (2013) y 86,9\% (2014). Según modelos matemáticos de simulación de brotes, considerando características de transmisibilidad, susceptibles y coberturas vacunación, se la población a fin disminuir riesgos epidemiológicos por ingresos de nuevos casos en una comunidad ${ }^{29}$. propone mantener coberturas superior o igual a $95 \%$ de
Figura 9. Porcentaje de cobertura de vacunación contra sarampión en niños de 1 año de edad. Chile 1980-2014. Fuente: Folleto de Inmunización de OPS. Sitio DEIS Ministerio de Salud, Chile. 
Figura 10. Porcentaje de cobertura de vacunación contra sarampión en niños de Primero Básico. Chile 1991-2014. Fuente: Folleto de Inmunización de OPS. Sitio DEIS Ministerio de Salud, Chile.

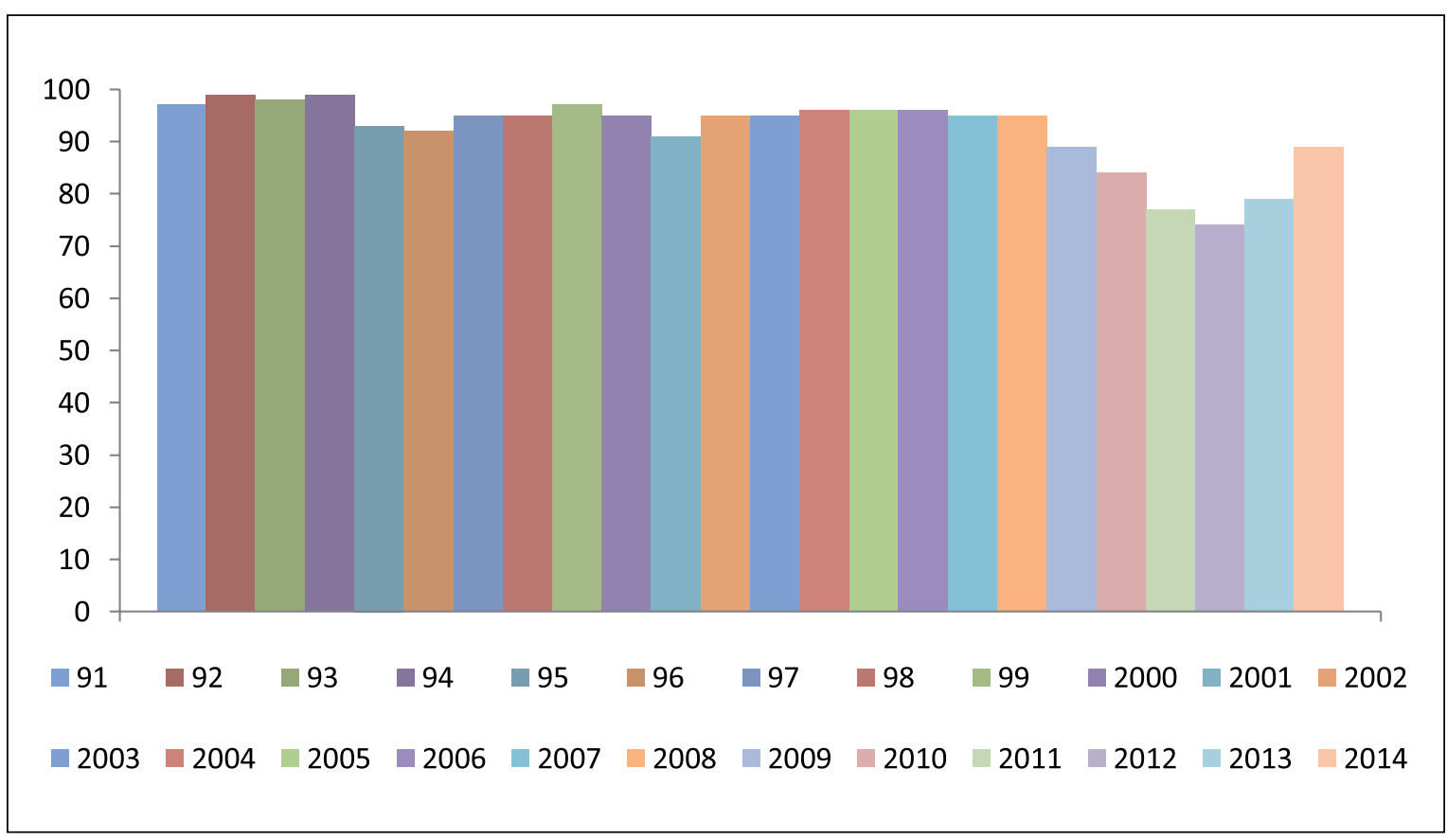

\section{Campañas de vacunación}

Independiente de las coberturas alcanzadas y dada la necesidad de asegurar una población inmune, además de la administración de vacuna según programa, con posterioridad a la última epidemia de sarampión ocurrida en Chile entre los años 1988 y 1989, se han realizado grandes esfuerzos por disminuir las tasas endémicas de sarampión, realizándose hasta la fecha dos campañas masivas de vacunación o de "puesta al día". Las coberturas de vacunación alcanzadas en estas dos primeras campañas fueron de $99,6 \%$ (1992) y $100 \%$ (1996), siendo vacunados niños y niñas bajo 15 años de edad.

La Primera Campaña Nacional de vacunación antisarampión concentrada en diez días, se efectuó entre el 6 al 16 de abril de 1992, focalizada en los niños de 9 meses a los 14 años 11 meses $^{30}$. El éxito de esta primera Campaña nacional se debió a la planificación de ella, que incluyó:

- Creación de una Comisión Nacional para la coordinación de acciones de capacitación y promoción, adecuación de recursos humanos, financieros, cadena de frío, transporte, insumos, elaboración de información, su análisis y evaluación.

- Elaboración de un plan de actividades coordinadas con los Servicios de Salud y liderado por el Departamento de Epidemiología del MINSAL.

- Inclusión de un Plan de Comunicación Social, basado en avisos de televisión con la participación de animadores infantiles de gran prestigio de diversos canales nacionales de televisión, comunicación radial, prensa, elaboración y difusión de folletos, afiches y trípticos. Los niños vacunados recibieron como estímulo un autoadhesivo con la frase "Yo estoy vacunado, Chao sarampión".

- Inclusión de organizaciones públicas y privadas, Universidades, Sociedades Científicas, Colegios profesionales de la Salud e institutos privados de Salud.

- Coordinación y participación intersectorial entre los Ministerios de Salud, Educación, Justicia, Defensa, Transporte y Telecomunicaciones ${ }^{31}$.

Todos elementos que a más de 20 años nos parecen relevantes de considerar para mejorar las coberturas de vacunación de enfermedades inmunoprevenibles en el país.

En el año 1996 se repitió la vacunación masiva focalizada en los niños mayores de 1 año y menores de 15 años, dado nuevamente por acúmulo de susceptibles, sumados los niños no vacunados y los vacunados no inmunizados por presencia de anticuerpos maternos, por respuesta inadecuada a la vacunación u otros factores. Esta segunda Campaña Nacional basada en la experiencia de la primera, logró una cobertura de $100 \%$ de la población objetivo. Los resultados operacionales de la primera y segunda Campaña Nacional de vacunación anti-sarampión determinaron que no se presentaran más casos de sarampión en niños, teniendo como base una vigilancia epidemiológica constante de casos, con base de exámenes de laboratorio en todos los casos con exantemas febriles.

Las campañas de vacunación de "seguimiento", son 
un componente esencial de la estrategia para erradicar el sarampión, y sugerencia de la OMS para mantener el estado de eliminación de la enfermedad. Estas campañas están dirigidas a todos los niños y niñas de 1 a 4 años 11 meses y 29 días de edad, aunque ya estén vacunados o hayan tenido la enfermedad. Hasta el momento se han realizado tres campañas de "vacunación de seguimiento", a saber: en el año 2001, donde se alcanzó una cobertura de $99 \%$; en el año 2005, donde se logró una cobertura de 93,2\% y en el año 2010-2011 alcanzando una cobertura de $75,2 \%$ según cifras reportadas desde el nivel central.

\section{Brotes post-campañas de vacunación}

- En 1997: Comuna de Pinto (Octava Región) y Región Metropolitana.

Se confirmaron casos con edades entre los 3 meses y los 36 años. De un total de 19 casos, tres $(15,7 \%)$ tenían menos de un año de edad, dos (10,5\%) tenían de 15 a 19 años, diez (52,6\%) tenían de 20 a 29 años y cuatro (21\%) tenían de 30 a 39 años. Nueve $(47,4 \%)$ trabajaban en el centro de esquí de Chillán. El brote se inició en el complejo turístico invernal, correspondiendo el caso primario a un turista brasileño. Simultáneamente, se presentaron 40 casos en la Región Metropolitana, 19 de ellos residían en el sector oriente de Santiago. No se logró establecer una relación directa con el brote de Pinto ni conocer con exactitud la fuente de contagio. Como medida de control de estos brotes se realizó una campaña de vacunación selectiva en todo el país dirigida a grupos considerados de riesgo. El grupo objetivo estuvo constituido por personas de 20 a 35 años de edad que trabajaran en empresas que tienen contacto permanente con extranjeros, en lugares de contacto con niños pequeños, estudiantes de las carreras de la salud y trabajadores de la salud en contacto con pacientes. Se vacunaron 232.438 personas, aproximadamente $56 \%$ de ellos trabajadores en contacto con extranjeros, $26 \%$ de área de la salud, 10\% personal de salas cuna y $9 \%$ de otros grupos ${ }^{28}$.

- En diciembre de 1998-febrero de 1999: Puerto Natales. En la ciudad de Puerto Natales ubicada en la Región de Magallanes, se presentó un brote de sarampión que tuvo una duración de siete semanas, afectó a 29 personas, que, al igual que en el brote de 1997, pertenecían a grupos etarios no vacunados: menores de un año (45\%) y mayores de 20 años $(55 \%)$. El caso primario correspondió a un niño de 13 meses de edad, detectado a través de la búsqueda activa en los registros del Servicio de Urgencia del Hospital local. Como medida de control se realizó una campaña de vacunación focalizada en los grupos de riesgos de las ciudades de Puerto Natales, Porvenir y Punta Arenas; se administró un total de 6.150 dosis de vacuna.
- En 2011: Se pesquisan tres nuevos casos importados, con un total de seis casos para el país. Todos los casos fueron notificados por centros privados en la Región Metropolitana. El primer caso corresponde a una azafata contagiada probablemente en Brasil y que en Santiago contagió a su hija lactante y esposo de 35 años. Luego se identificó una mujer de 47 años que viajó y se enfermó al regreso desde E.U.A. contagiando en Santiago a un profesional de la salud de 39 años durante la consulta médica. En las dos importaciones descritas, se identificó el genotipo viral D4. En junio de 2011, se identificó el sexto caso, en una mujer de 30 años, a su regreso de vacaciones de Tailandia y Malasia, cuyo genotipo resultó ser D9 circulante en esos países asiáticos ${ }^{23}$.

\section{- En 2015: Región Metropolitana}

Al 15 de julio se han confirmado 9 casos de sarampión en la Región Metropolitana constituyendo esto un brote que se inició el 12 de mayo, con la aparición de los primeros síntomas del primer caso confirmado. El caso primario corresponde a un chileno que viajó a China. El genotipo viral identificado en el brote corresponde a H1, circulante en Asia. Todos los casos confirmados, a excepción de dos casos, son hombres y, según edad, se distribuyen en $<1$ año ( 2 casos), $>10$ años ( 1 caso), $>20$ años ( 2 casos), > 30 años ( 3 casos); $>40$ años (1 caso). Se ha vacunado a la fecha aproximadamente a 2.777 personas.

La circulación del virus sarampión en el mundo, con casos y muertes, actualmente afecta a unos 160 países, y dada su alta contagiosidad, la falta de programas que garanticen coberturas de vacunación que idealmente se aproximen a $100 \%$ en los niños, a los que se suman las falsas creencias del eventual daño que producirían, mantiene la vigencia de alerta en los sistemas de salud pública $^{32}$. Se suma el hecho que la vacuna no garantiza per se la inmunización absoluta, por respuesta inmunológica individual, eventual presencia de anticuerpos maternos, problemas en cadena de frío u otras causas, dejando anualmente un grupo de susceptibles a incluir en campañas recurrentes de vacunación. La particular visión de algunos padres que retardan o niegan la inmunización de hijos susceptibles, hoy en día se encuentra en el tapete de discusión ya que de todas formas impacta en la salud pública de los distintos países y nos obliga a reforzar la entrega de información con base científica, e incluyendo conceptos éticos y legales ${ }^{33}$.

Un mero análisis de los años 2010 a 2013 de las coberturas con vacuna tresvírica colocada al año de edad en nuestro país, muestra que no se han vacunado en estos tres años, un total de 60.047 niños, sumando 5\% de niños vacunados y no inmunizados en este período de un 
total de 94.726 niños susceptibles de hacer sarampión. Sumado otra importante cantidad de susceptibles nacidos en 2014, refuerzan la necesidad de contar este año con una exitosa campaña de revacunación programada por el MINSAL para octubre de 2015, con meta ideal de superar una cobertura de $95 \%$ de los niños población objetivo.

En la situación actual con brote de sarampión presente en la Región Metropolitana, debemos insistir en seguir las indicaciones incluidas en la normativa vigente ${ }^{34}$, a fin mantener una oportuna notificación de casos -responsabilidad del médico tratante-implementar el estudio con las tomas de muestra respiratoria por aspirado nasofaríngeo y de sangre recomendadas para ser derivadas al ISP, dejando al nivel central la coordinación de las acciones de bloqueo con vacunación de contactos y administración de inmunoglobulina normal (IM) a quienes no pueden recibir vacuna (menores de un año, mujeres embarazadas y pacientes inmunocomprometidos).

De igual forma, tener presente las recomendaciones entregadas a viajeros definidos como susceptibles ${ }^{35}$ que indica vacunar a las personas nacidas entre 1971 y 1981 que viajan al exterior sin antecedente de haber cursado la enfermedad o de haber recibido dos dosis de vacuna después del año de edad; lactantes entre 6 meses y 11 meses 29 días (quienes igual deben luego recibir vacuna según programa vigente) y menores entre 1 y 6 años de edad que tienen sólo una dosis administrada.

\section{Comentarios finales}

Los casos registrados actualmente en el país que suman nueve en la Región Metropolitana al 14 de julio de 2015, nos ofrece una gran oportunidad para promover con argumentos científicos y operacionales, la protección que ofrecen las vacunas a las personas.

Las propuestas de acciones para el control y erradicación del sarampión se resumen en:

- Mantener informada a la población sobre la seguridad que ofrecen las vacunas en las personas.

- Analizar las coberturas de vacunaciones en forma sistemática por comunas y Servicios de Salud.
- Mantener una vigilancia epidemiológica activa a todos los casos sospechosos de sarampión de cualquier edad.

- Junto con ello, reforzar la Vigilancia Epidemiológica para contar con una capacidad de respuesta oportuna frente a la aparición de un caso, sea autóctono o importado.

- Analizar sistemáticamente las poblaciones susceptibles, basado en información de los niños no vacunados y los no inmunizados por cohortes, planificando campañas nacionales de vacunación en poblacionesobjetivo.

Los costos ya invertidos en vacunaciones realizadas por décadas, a través de programas sistemáticos y Campañas Nacionales periódicas, ameritan abordar con una planificación y política, el control del sarampión y otras enfermedades inmuno-prevenibles, basándose en evidencia científica en Salud Pública, de la cual Chile tiene una historia en la cual respaldar acciones que beneficien a la población. Ello además se encuentra enunciado en el Objetivo Estratégico 1 de las Metas de la década 20112020 "Reducir la carga sanitaria de las Enfermedades Transmisibles y contribuir a disminuir el impacto social y económico"36.

\section{Resumen}

Sarampión una de las más importantes enfermedades inmuno-prevenibles, se mantiene como foco de preocupación en el mundo, con elevada carga de morbilidad y mortalidad. Particularmente en América, región declarada libre de esta enfermedad en 2010 por la OMS, se siguen identificando casos importados que originan brotes de diferente magnitud en personas susceptibles, habitualmente no vacunados, situación recientemente diagnosticada en Santiago, ciudad capital de Chile. En esta revisión, se presenta características del agente etiológico, de la enfermedad, aspectos epidemiológicos con foco en datos históricos nacionales, el impacto de los programas de vacunación, la ocurrencia de brotes en Chile, para contribuir al conocimiento y enfrentamiento de este siempre presente problema de salud pública.

\section{Referencias bibliográficas}

1.- De Quadros C A, Izurieta H, Carrasco P, Brana M, Tambini G. Progress toward measles eradication in the region of the Americas. J Infect Dis 2003; 187 (Suppl 1): S102-10.

2.- Moss W, Griffin D. Measles. Lancet 2012: 379: 153-64.

3.- William J. Moss and Diane E. Griffin Global measles elimination Nature 2006; 4: 900-8.

4.- Dudgeon J A. Measles vaccines. Br Med Bull 1969; 25 (2): 153-8.

5.- Avendaño L F, Ferrés M, Spencer E. Virología Clínica. Editorial Mediterráneo 2011; 178-81.

6.- Feigin and Cherry`s Textbook of Pediatric Infectious Diseases, $7^{\circ}$ edition, Elsevier Saunders 2014: Measles virus, Cherry J, Capítulo 179: 2373-95.
7.- de Vries R, Mesman A, Geijtenbeek T, Duprex W, Swart R. The pathogenesis of measles, Curr Opin Virol 2012; 2: 248-55.

8.- de Swart R. The pathogenesis of measles revisited Pediatr Infect Dis J 2008; 27: S84-8.

9.- Delpeut S, Noyce R, Siu R, Richardson C. Host factors and measles virus replication, Curr Opin Virol 2012; 2: 773-83.

10.- de Witte L, Abtv M, Schneider-Schaulies S, 
Van Kooyk Y, Geijtenbeek T B H. Measles virus target DC-SIGN to enhance dendritic cell infection. J Virol 2006; 80: 3477-86.

11.- Cox R, Plemper R. The paramyxovirus polymerase complex as a target for next generation anti-paramyxovirus therapeutics. Front Microbiol 2015; 6: 459.

12.- Rima B, Duprex W. New concepts in measles virus replication: Getting in and out in vivo and modulating the host cell environment. Virus Res 2011; 162: 47-62.

13.- Duke T, Mgone C S. Measles: not just another viral exanthem Lancet 2003; 361: 763-73.

14.- Measles vaccines: WHO position paper. Weekly Epidemiol Rec, 28 august 2009; 35: 349-60.

15.- Global Programme for Vaccines and Immunization/Expanded Programme on Immunization. Using Surveillance Data and Outbreak Investigations to Strengthen Measles Immunization Programmes (WHO/EPI/ GEN/96.02).Geneva, Switzerland: World Health Organization; 1996.

16.- Robert L. Is measles next? Science 2015; 348 : 959-63.

17.- Bellini W J, Helfand R F. The challenges and strategies for laboratory diagnosis of measles in an international setting. J Infect Dis 2003; 187 (suppl 1): S283-90.

18.- Rota P A, Featherstone D A, Bellini W J. Molecular epidemiology of measles virus. Curr Top Microbiol Immunol 2009; 330: 129-50.

19.- Rota P A, Brown K, Mankertz A, Santibáñez S, Shulga S, Muller C, et al. Global distribution of measles genotypes and measles molecular epidemiology J Infect Dis 2011; 204: S514-23.
20.- WHO. Strategies for reducing global measles mortality. Weekly Epidemiol Rec 2000; 75: 41116.

21.- Condack C, Grivel J C, Devaux P, Margolis L, Cattaneo R. Measles virus vaccine attenuation: suboptimal infection of lymphatic tissue and tropism alteration. J Infect Dis 2007; 196: 54149.

22.- Nota descriptiva $\mathrm{N}^{\circ} 286$, febrero de 2015 en http://www.who.int/mediacentre/factsheets/ fs $286 / \mathrm{es} /$.

23.- Documentación para la verificación de la eliminación del sarampión, Doris Gallego editora. MINSAL-OPS 2011.

24.- Laval E. La epidemia de sarampión de 18991900 en Chile y la creación del primer hospital de niños de Santiago. Rev Chilena Infectol 2002; 2: 121-3.

25.- Servicio Nacional de Salud. Técnicas de Vacunación, Aislamiento, Toma de Muestras y Otras. Sub-Depto. de Protección de la Salud. Normas de Epidemiología. Editado por la Sección Educación para la Salud. Santiago de Chile 1972.

26.- Manual de Inmunizaciones. Departamento Apoyo Programas, Ministerio de Salud. Octubre de 1981.

27.- PAI Boletín Informativo OPS. Programa Ampliado de Inmunización en las Américas. Año I, No 1 mayo de 1979.

28.- Jiménez de la Jara J. Control del Sarampión en Chile. Campaña Nacional de Inmunización 1992. Abril de 1995. Capítulo 3, Nizar Ajjan Desarrollo y Aplicación de la Vacuna Antisarampión.

29.- Liu F, Enanoria W, Zipprich J, Blumberg S,
Harriman K, Ackley S, et al. The role of vaccination coverage, individual behaviors, and the public health response in the control of measles epidemics: an agent-based simulation for California. BMC Public Health 2015; 15: 447-62.

30.- Toro J. Propuesta de control del sarampión en Chile. Ministerio de Salud, Serie Informes Técnicos $\mathrm{N}^{\circ}$ 3, Depto. de Epidemiología. Diciembre de 1991.

31.- Toro J. El Proyecto de la Campaña masiva antisarampión: Chile 1992. Control del Sarampión en Chile. Campaña Nacional de Inmunización 1992". Editorial Dolmen Estudio 1995; 123-44.

32.- Cutts F, Lessler J, Metcalf C H. Measles elimination: progress, challenges and implications for rubella control. Expert Rev Vaccines 2013; 12 (8): 917-32.

33.- Gostin L. Law, ethics, and public health in the vaccination debates politics of the measles outbreak. JAMA 2015; 11: 1099-100.

34.- Circular B 51/27 del 23 de julio de 2010 Actualización Enfermedades eliminadas de América: vigilancia integrada SarampiónRubeola. Sub Secretaria de salud Pública. Departamento de Epidemiologia. Ministerio de Salud Chile.

35.- Ordinario B 27/523 del 04 de marzo de 2015. Vacunación de viajeros susceptibles con vacuna trivírica. Sub Secretaría de Salud Pública. Departamento de vacunas e inmunizaciones. Ministerio de Salud Chile.

36.- Ministerio de Salud. Estrategia Nacional de Salud para el cumplimiento de los Objetivos Sanitarios de la Década 2011-2020. Chile, 247 págs. 